\title{
Pulmonary metastasectomy for pulmonary metastasis of breast cancer has a limited prognostic impact: a multi-institutional retrospective analysis
}

\author{
Makoto Endoh ${ }^{1}$, Satoshi Shiono ${ }^{1}$, Yoshikane Yamauchi ${ }^{2}$, Mingyon Mun $^{3}$, Norihiko Ikeda ${ }^{4}$, \\ Hiroshi Hashimoto ${ }^{5}$, Hirotoshi Horio ${ }^{6}$, Hisao Asamura ${ }^{7}$, Ichiro Yoshino, Haruhisa Matsuguma ${ }^{8}$, \\ Jun Nakajima $^{10}$, Takahiko Oyama ${ }^{11}$, Yasushi Shintani ${ }^{12}$, Mitsuo Nakayama ${ }^{13}$, Noriyuki Matsutani ${ }^{2}$, \\ Masafumi Kawamura ${ }^{2}$; on behalf of the Metastatic Lung Tumor Study Group of Japan
}

${ }^{1}$ Department of Thoracic Surgery, Yamagata Prefectural Central Hospital, Yamagata, Japan; ${ }^{2}$ Division of General Thoracic Surgery, Teikyo University, School of Medicine, Tokyo, Japan; ${ }^{3}$ Department of Thoracic Surgical Oncology, The Cancer Institute Hospital, Tokyo, Japan; ${ }^{4}$ Division of Thoracic and Thyroid Surgery, Tokyo Medical University, Tokyo, Japan; ${ }^{5}$ Department of Thoracic Surgery, National Defense Medical College, Saitama, Japan; ${ }^{6}$ Department of Thoracic Surgery, Tokyo Metropolitan Cancer and Infectious Diseases Center Komagome Hospital, Tokyo, Japan; ${ }^{7}$ Division of Thoracic Surgery, Keio University School of Medicine, Tokyo, Japan; ${ }^{8}$ Department of General Thoracic Surgery, Chiba University Graduate School of Medicine, Chiba, Japan; ${ }^{9}$ Division of Thoracic Surgery, Tochigi Cancer Center, Tochigi, Japan; ${ }^{10}$ Department of Thoracic Surgery, Graduate School of Medicine and Faculty of Medicine, The University of Tokyo, Tokyo, Japan; ${ }^{11}$ Department of General Thoracic Surgery, National Hospital Organization Tokyo Medical Center, Tokyo, Japan; ${ }^{12}$ Department of General Thoracic Surgery, Osaka University Graduate School of Medicine, Osaka, Japan; ${ }^{13}$ Department of General Thoracic Surgery, Saitama Medical Center, Saitama, Japan

Contributions: (I) Conception and design: M Endoh, S Shiono; (II) Administrative support: M Endoh, S Shiono; (III) Provision of study materials or patients: All authors; (IV) Collection and assembly of data: All authors; (V) Data analysis and interpretation: M Endoh, S Shiono; (VI) Manuscript writing: All authors; (VII) Final approval of manuscript: All authors.

Correspondence to: Satoshi Shiono, MD. Department of Thoracic Surgery, Yamagata Prefectural Central Hospital, 1800, Ooazaaoyagi, Yamagata 9902292, Japan. Email: sshiono@ypch.gr.jp.

Background: Pulmonary metastasectomy (PM) for breast cancer-derived pulmonary metastasis is controversial. This study aimed to assess the prognostic factors and implication of PM for metastatic breast cancer using a multi-institutional database.

Methods: Clinical data of 253 females with pulmonary metastasis of breast cancer who underwent PM between 1982 and 2017 were analyzed retrospectively.

Results: The median patient age was 56 years. The median follow-up period was 5.4 years, and the median disease-free interval (DFI) was 4.8 years. The 5- and 10 -year survival rates after PM were $64.9 \%$ and $50.4 \%$, respectively, and the median overall survival was 10.1 years. Univariate analysis revealed that the period of PM before 2000, a DFI <36 months, lobectomy/pneumonectomy, large tumor size, and lymph node metastasis were predictive of a worse overall survival. In the multivariate analysis, a DFI $<36$ months, large tumor size, and lymph node metastasis remained significantly related to overall survival. The 5- and 10-year cancer-specific survival rates after PM were $66.9 \%$ and $54.7 \%$, respectively, and the median cancer-specific survival was 13.1 years. Univariate analyses revealed that the period of PM before 2000, DFI <36 months, lobectomy/pneumonectomy, large tumor size, lymph node metastasis, and incomplete resection were predictive of a worse cancer-specific survival. Multivariate analysis confirmed that a DFI $<36$ months, large tumor size and incomplete resection were significantly related to cancer-specific survival.

Conclusions: As PM has limited efficacy in breast cancer, it should be considered an optional treatment for pulmonary metastasis of breast cancer.

Keywords: Pulmonary metastasis; metastasectomy; breast cancer 
Submitted Apr 28, 2020. Accepted for publication Sep 24, 2020.

doi: $10.21037 /$ jtd-20-1788

View this article at: http://dx.doi.org/10.21037/jtd-20-1788

\section{Introduction}

Breast cancer has the highest incidence rate among all female cancers (1). Distant metastasis of breast cancer occurs primarily in the bone, lung, and liver, with pulmonary metastasis constituting $15-25 \%$ of metastatic breast cancer cases (2). Metastatic breast cancer is treated primarily with systemic therapies. However, with the advent of treatments for various malignancies, the concept of oligometastasis (3), a type of distant metastasis for which local therapies might be curative, was proposed.

Pulmonary metastasectomy $(\mathrm{PM})$ is a common treatment for selected patients with pulmonary metastasis. Patients with complete resection without residual lesions, a diseasefree interval (DFI) $\geq 36$ months, and solitary pulmonary metastasis may have a better prognosis after PM $(4,5)$. Because there are no randomized studies validating the survival benefit of PM, its efficacy is controversial $(6,7)$, as is its role in the treatment of pulmonary metastasis of breast cancer. The National Comprehensive Cancer Network Guideline for Breast Cancer, version 3.2019, recommends systemic treatment for M1 or recurrent breast cancer (8).

The 5 -year survival rate of patients with pulmonary metastasis of breast cancer after PM is $35-60 \%(2,9-17)$. A few studies have reported that patients with pulmonary metastasis of breast cancer who underwent PM had a better survival than those who did not (11-13). A meta-analysis including 1,937 patients reported that the 5-year survival rate after $\mathrm{PM}$ was $46 \%$, and that the factors predicting a worse prognosis were a shorter DFI ( $<3$ years), incomplete resection, multiple pulmonary metastases $(>1)$ and a negative hormone receptor status in the pulmonary metastasis (14). Conversely, in other studies, incomplete resection did not affect survival $(13,15,17)$. If the prognosis after incomplete $\mathrm{PM}$ is similar to that after complete PM, then PM for pulmonary metastasis of breast cancer provides no benefit to the patient. This study aimed to assess the prognostic factors and implication of PM for pulmonary metastasis of breast cancer using a Japanese multi-institutional database.

We present the following article in accordance with "The Strengthening the Reporting of Observational Studies in Epidemiology (STROBE) Statement" reporting checklist (18) (available at http://dx.doi.org/10.21037/jtd-20-1788).

\section{Methods}

\section{Patients and study design}

We retrospectively reviewed the database of the Metastatic Lung Tumor Study Group of Japan, which was established in 1980 and consists of prospectively collected data from patients undergoing PM for curative intent from 26 institutions. The indication, procedure, and approach of surgical resection for PM were independently determined by each institution. As reported in a previous study (19), general indications for surgical resection of pulmonary metastasis followed the criteria of Thomford et al. (20): the primary lesion was under control or was planned to be under control; there were no metastases to other organs; and the patient's general condition was good enough to withstand surgery.

Patients were followed up with chest CT scan twice a year to detect the recurrence of breast cancer including the pulmonary metastasis, and additional imaging studies were performed at the discretion of the treating physician. Survival outcome surveillance was subsequently conducted at 1-year intervals by the registration center. Data for the following parameters were collected: sex, age, primary tumor histology, primary tumor stage, primary tumor treatment, hormone receptor status, date of surgery for the primary tumor, type of surgery, resection status of PM, date of metastasis, DFI, laterality of the pulmonary metastasis, tumor size, number of resected metastases, date of PM, other treatments, and site and date of recurrence. The DFI was calculated from the initial treatment of the primary tumor to the diagnosis of pulmonary metastasis. Complete resection of the pulmonary lesion was based on the judgments of each institution.

From the database, based on histopathological studies, we enrolled 387 patients diagnosed with pulmonary metastases originating from breast cancer between December 1982 and March 2017. After excluding patients of incomplete resection of the primary breast cancer, patients of primary breast sarcoma, patients that underwent surgery for the purpose of biopsy, and males, 352 patients were eligible for analysis. Furthermore, after excluding patients with insufficient data, a total of 253 females diagnosed with breast cancer between the stipulated years constituted the 


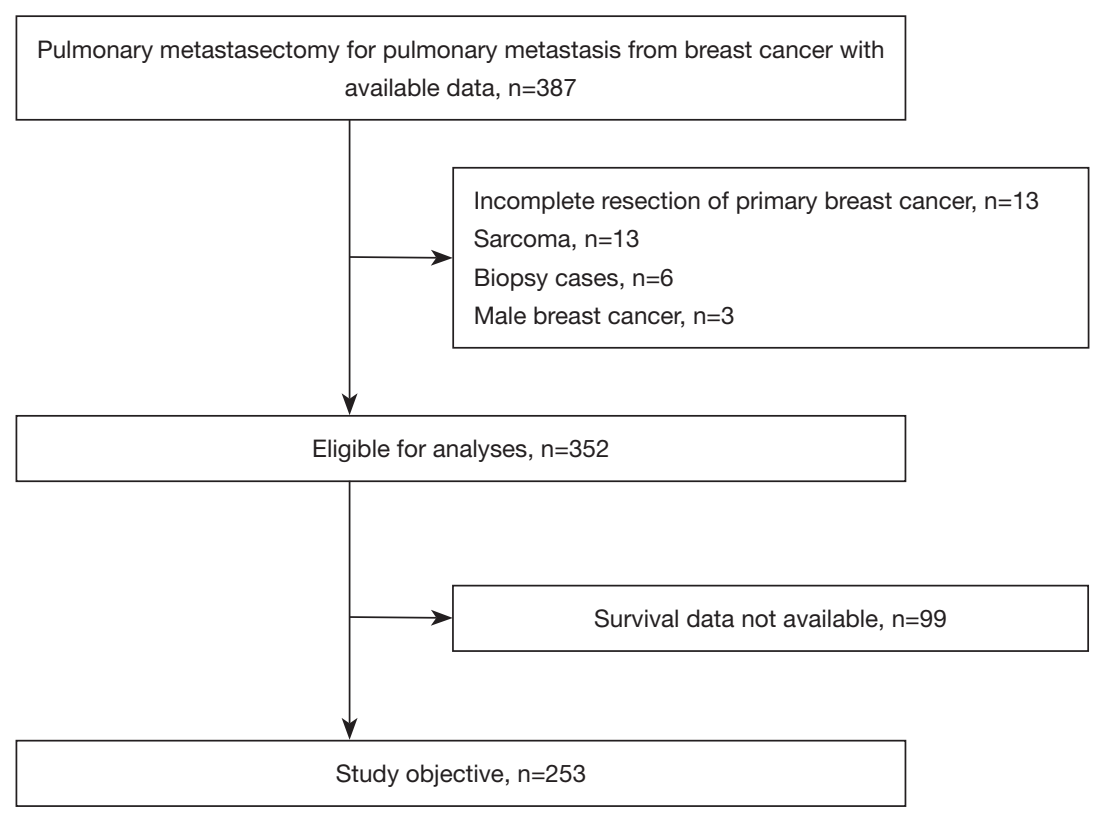

Figure 1 Patient enrollment schema.

study population. Surgical outcomes and prognostic factors were analyzed retrospectively (Figure 1).

The study was conducted in accordance with the Declaration of Helsinki (as revised in 2013). The study was approved by the ethics committees of the affiliated institutions (No. 2018-94; 7 March 2018) and the need for individual consent for this retrospective analysis was waived as long as the patient data remain anonymous.

\section{Statistical analysis}

Categorical data are presented as numbers (\%) and continuous variables as medians (range). The follow-up period was defined as the time from the date of PM to the last hospital visit or death from any cause. The overall survival and cancer-specific survival rates were estimated using the Kaplan-Meier method. Overall survival was measured from the date of PM to death from any cause or, if still alive, the last hospital visit. Cancer-specific survival was measured from the date of PM to the death from breast cancer. Censoring was performed at death for non-cancerrelated deaths or the last hospital visit for patients still alive at the end of the study. The diagnosis of cancer progression was judged by each institution.

To identify the prognostic factors for overall survival and cancer-specific survival, univariate and multivariate analyses were performed using Cox proportional-hazards regression models. As the data for primary breast cancer stage, hormone receptor status, and preoperative treatment were insufficient, we did not explore the relationships of these factors with prognosis. Based on previous metaanalyses (14), we used a cut-off DFI of 36 months in the regression analyses. The data were analyzed using the JMP software package, version 13.0.0 (SAS Institute, Inc., Cary, NC, USA). A P value $<0.05$ was considered statistically significant.

\section{Results}

Characteristics of the 253 study patients are summarized in Table 1 . The median DFI was approximately 5 years. Of the patients, $215(85 \%)$ had a solitary pulmonary nodule and 38 (15\%) had multiple pulmonary nodules. Regarding the PM procedure, lobectomy was performed in approximately half of the cases. The rate of lobectomy decreased over the years: between 1982 and 1999, it was 55\% (48/88 patients), between 2000 and 2009, it was 49\% (37/76 patients), and between 2010 to 2017, it was 36\% (31/89 patients) $(\mathrm{P}<0.001)$. Lymph node dissection was performed in 122 (48\%) patients, and 55 patients had lymph node metastasis.

We conducted a sensitivity analysis of the patient's backgrounds between the following two periods: 19821999 and 2000-2017. There were significant differences in age, DFI, number of tumors, tumor diameter, surgical 
Table 1 Characteristics of the patients who underwent pulmonary metastasectomy

\begin{tabular}{|c|c|}
\hline Characteristics & $\mathrm{n}[\%]$ or median [range] ${ }^{\mathrm{a}}$ \\
\hline \multicolumn{2}{|c|}{ Period of pulmonary metastasectomy } \\
\hline 1982-1999 & 88 [35] \\
\hline 2000-2009 & 76 [30] \\
\hline 2010-2017 & 89 [35] \\
\hline Age, years & 56 [32-82] \\
\hline Disease-free interval, years & $4.8[0-31]$ \\
\hline Number of metastases & $1[1-7]$ \\
\hline Tumor diameter, cm & $1.5[0.3-9.0]$ \\
\hline \multicolumn{2}{|l|}{ Procedure } \\
\hline Wedge resection & $113[44]$ \\
\hline Segmentectomy & $22[9]$ \\
\hline Lobectomy & $116[46]$ \\
\hline Pneumonectomy & $2[1]$ \\
\hline \multicolumn{2}{|l|}{ Lymph node dissection } \\
\hline None & $131[52]$ \\
\hline Hilar & $44[17]$ \\
\hline Mediastinal & 78 [31] \\
\hline \multicolumn{2}{|l|}{ Lymph node metastasis } \\
\hline None & $197[78]$ \\
\hline Hilum & 34 [13] \\
\hline Mediastinum & $22[9]$ \\
\hline \multicolumn{2}{|l|}{ Resection status } \\
\hline Complete & $229[91]$ \\
\hline Incomplete & $24[9]$ \\
\hline \multicolumn{2}{|l|}{ Preoperative therapy } \\
\hline Yes & $57[21]$ \\
\hline No & $196[79]$ \\
\hline \multicolumn{2}{|l|}{ Postoperative therapy } \\
\hline Yes & $142[56]$ \\
\hline No & 111 [44] \\
\hline
\end{tabular}

procedure, lymph node dissection, and lymph node metastasis between the periods. However, resection margin of metastasectomy showed no difference in the ratio of preoperative and postoperative therapy outcomes (Table S1). Table 2 shows the characteristics of the primary breast cancers during breast surgery in the patients. Invasive ductal carcinoma was the predominant histology. We did not have information on hormone receptor statuses in approximately half of the patients.

One patient died of pulmonary embolism within 30 days after PM and two patients died of acute exacerbation of interstitial pneumonia within 90 days. The $30-$ and 90 -day mortality rates were $0.4 \%$ and $0.8 \%$, respectively. The Kaplan-Meier estimate of the median follow-up after PM was 5.4 (range, 0-24.0) years. At the time of analysis, $171(67.6 \%)$ patients were alive, 73 (28.9\%) had died of breast cancer, and $9(3.6 \%)$ had died of causes unrelated to breast cancer. Among the 171 surviving patients, 131 were recurrence free.

Of the total 253 patients, recurrence developed after PM in $110(43 \%)$ as follows: extrathoracic metastasis in $49(45 \%)$ patients, intrathoracic lesion in $28(25 \%)$ patients, and as both intra- and extrathoracic metastases in 4 (4\%) patients. There was no information regarding the recurrence site in 29 patients.

The 5- and 10-year survival rates after PM were $64.9 \%$ and $50.4 \%$, respectively, and the median overall survival was 10.1 years (Figure $2 A$ ). Univariate analysis revealed that the period of PM before 2000, a DFI $<36$ months, lobectomy or pneumonectomy, large tumor size, and lymph node metastasis were predictive factors of a worse overall survival (Table 3). Incomplete resection of the pulmonary metastasis was not related to overall survival. Multivariate analysis confirmed that a DFI $<36$ months, large tumor size, and lymph node metastasis were significantly related to overall survival. The 5- and 10-year cancer-specific survival rates after PM were $66.9 \%$ and $54.7 \%$, respectively, and the median cancer-specific survival was 13.1 years (Figure $2 B$ ).

Univariate analysis revealed that the period of PM before 2000, DFI <36 months, lobectomy or pneumonectomy, large tumor size, lymph node metastasis, and incomplete resection were predictive factors of a worse cancer-specific survival (Table 4). A DFI $<36$ months, large tumor size, and incomplete resection remained significant in the multivariate analysis. Differing from overall survival, incomplete resection was found to be significantly related to cancer-specific survival in the multivariate analysis.

To explore the possible reasons for incomplete resection, the patient's characteristics were evaluated according to the extent of resection of the pulmonary metastasis. The proportion of patients that had sublobar resection for 
Table 2 Characteristics of the primary breast cancer

\begin{tabular}{|c|c|}
\hline Characteristics & $\mathrm{n}[\%]$ \\
\hline \multicolumn{2}{|l|}{ Histology } \\
\hline Invasive ductal carcinoma & 215 [85] \\
\hline Other & $31[12]$ \\
\hline NA & 7 [3] \\
\hline \multicolumn{2}{|l|}{ Stage at breast surgery } \\
\hline I & $40[16]$ \\
\hline II & $126[50]$ \\
\hline III & $25[10]$ \\
\hline IV & 6 [2] \\
\hline NA & 56 [22] \\
\hline \multicolumn{2}{|l|}{ Estrogen receptor expression } \\
\hline Positive & $75[30]$ \\
\hline Negative & 69 [27] \\
\hline NA & 109 [43] \\
\hline \multicolumn{2}{|c|}{ Progesterone receptor expression } \\
\hline Positive & 62 [25] \\
\hline Negative & $77[30]$ \\
\hline NA & $114[45]$ \\
\hline \multicolumn{2}{|l|}{ HER2 expression } \\
\hline Positive & 55 [22] \\
\hline Negative & $44[17]$ \\
\hline NA & $154[61]$ \\
\hline \multicolumn{2}{|l|}{ Preoperative treatment } \\
\hline Yes & $26[10]$ \\
\hline No & $129[51]$ \\
\hline NA & 98 [39] \\
\hline \multicolumn{2}{|l|}{ Postoperative treatment } \\
\hline Yes & $216[85]$ \\
\hline No & 29 [12] \\
\hline NA & 8 [3] \\
\hline
\end{tabular}

NA, data not available

multiple metastases was higher in incomplete resection cases (Table 5). Moreover, the proportion of patients who received postoperative treatment after PM was higher in incomplete resection cases.

\section{Discussion}

As metastatic breast cancer is considered a systemic disease, chemotherapy and hormonal therapy are recognized as the mainstay therapies (8). However, PM may confer a survival benefit in selected patients with isolated pulmonary metastasis derived from breast cancer. A longer DFI $(2,9,12-14,16)$, hormone receptor positivity $(10,12,14,17)$, smaller number of pulmonary metastases $(10,14)$, smaller tumor diameter $(10,16)$, unilateral metastasis (9), and primary breast cancer stage (13) were reported as factors predicting a better prognosis.

In this study, the multivariate analysis revealed that a DFI $<36$ months, large tumor size, and lymph node metastasis were significantly associated with worse overall survival, and a DFI $<36$ months, the size of the pulmonary metastatic nodule, and incomplete resection of PM were significantly associated with worse cancer-specific survival. However, since the follow-up duration and modalities used for postoperative monitoring can influence the DFI, the role of the DFI as a prognostic factor might be controversial.

We revealed that the DFI and tumor diameter were predictive of both overall survival and cancer-specific survival. Incomplete resection was identified as a poor prognostic factor for cancer-specific survival in this study; however, it was not a significant prognostic factor for overall survival in both the univariate and multivariate analyses. Therefore, complete resection was not a significant prognostic factor contributing to survival, and the resection of breast cancer lung metastases was considered to be controversial, as reported in some previous studies; however, the number of incomplete resection cases (24/253, $9 \%$ ) was as small events in this study, therefore univariate and multivariate analyses could be underpower using Cox proportional-hazards regression models.

As gathered from a large registry of 5206 patients who underwent PM, the 5-year survival rate was only $13 \%$ after incomplete PM, while it was $36 \%$ after complete PM (4). Similar to our findings, incomplete resection of pulmonary metastasis of breast cancer was reported not to be a significant prognostic factor $(13,15-17)$. There are a several reasons that could explain why incomplete resection does not affect survival. First, patients who underwent incomplete resection more frequently had multiple pulmonary metastases, underwent sublobar resection, and received postoperative therapy after PM than the patients who underwent complete resection (Table 5). Given that 
A

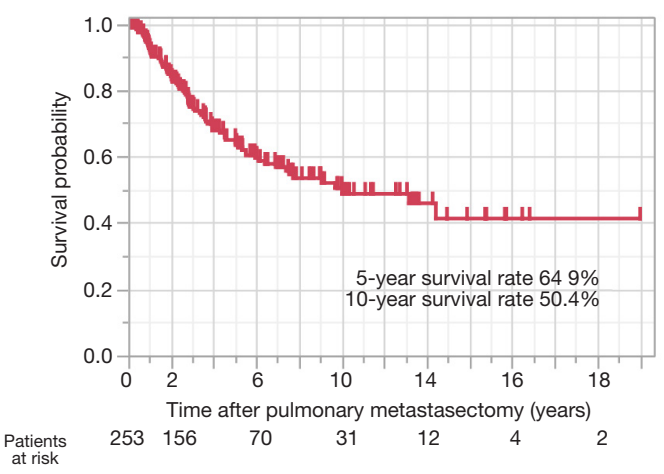

B

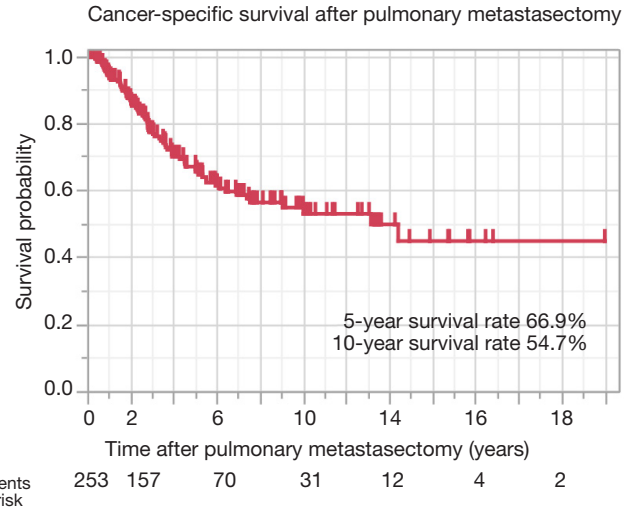

Figure 2 Kaplan-Meier curve for overall survival (A) and for cancer-specific survival after pulmonary metastasectomy (B).

metastatic breast cancer is a systemic disease, chemotherapy or hormonal therapy might be effective.

Second, we defined incomplete resection as $\mathrm{R} 1$ (microscopic incomplete resection) or R2 (macroscopic incomplete resection) in this study. Because of the small number of R1 and R2 cases ( $\mathrm{n}=24,9 \%)$, statistical analysis could not be performed. It is possible that there is a prognostic difference between $\mathrm{R} 1$ and $\mathrm{R} 2$ resection cases. Planchard et al. revealed a significantly worse prognosis among patients with unresectable pulmonary metastasis of breast cancer than among those who underwent incomplete resection (16), suggesting that the definition of incomplete resection might have affected the current results.

Regardless of this, the prognostic impact of PM for pulmonary metastasis derived from breast cancer does not appear to be strong compared to that of PM for pulmonary metastasis derived from other primary cancers. The recurrence rate after PM for pulmonary metastasis of breast cancer is reportedly high. In a previous study, even after complete resection of pulmonary metastasis derived from breast cancer, only $15 \%(19 / 125)$ of patients were alive without recurrence (16). In the current study, recurrence after PM developed in 110 of the total 253 (43\%) patients and in 93 of the $229(40.6 \%)$ patients with complete resection. This high recurrence rate after PM should not be ignored and suggests that local therapy alone cannot control metastatic breast cancer.

PM for pulmonary metastasis derived from breast cancer has another crucial role for the differential diagnosis. In clinical practice, we frequently encounter patients with breast cancer who have developed isolated lung nodules. Therefore, the radiological and pathological differential diagnosis of primary lung cancer from pulmonary metastasis of breast cancer can be challenging. Rena et al. investigated solitary pulmonary nodules in 79 patients with breast cancer; of them, 27 (34.1\%) developed pulmonary metastasis, and 38 (48.1\%) developed primary lung cancer (21).

In patients who underwent surgery for pulmonary nodules after breast cancer, the frequency of multiple pulmonary nodules was significantly the highest among those with metastatic breast cancer $(64.1 \%)$, primary lung cancer (33.3\%) and other histologies (28.6\%) (22). In our study, approximately half of the patients underwent lobectomy as the PM procedure, which might reflect the difficultly with differential diagnosis between primary lung cancer and pulmonary metastasis. Furthermore, surgical resection of nodules in patients with a history of breast cancer is a powerful diagnostic and treatment tool, and collecting samples of metastasized breast cancer might provide useful information for further treatment $(17,21)$.

Compared with previous studies, we demonstrated better overall survival in our population, with 5 - and 10 -year survival rates of $65 \%$ and $50 \%$, respectively (Table 6) $(2,9,10,12,13,16,17)$. Because this study population, including 89 patients who underwent PM between 2010 and 2017, underwent surgery relatively recently, the survival rates might be higher than those reported in previous studies. However, approximately half of the patients who underwent PM were alive with recurrence at the end of the study. The advent of multimodal treatments might result in improved surgical outcomes.

\section{Limitations}

The current study has a few fundamental limitations due to the retrospective analysis of multi-institutional registry data, 
Table 3 Prognostic factors for overall survival after pulmonary metastasectomy ${ }^{a}$

\begin{tabular}{|c|c|c|c|c|c|c|}
\hline Variables & \multicolumn{3}{|c|}{ Univariate analysis } & \multicolumn{3}{|c|}{ Multivariate analysis } \\
\hline \multicolumn{7}{|l|}{ Period of metastasectomy } \\
\hline 1982-1999 & 1.82 & $1.16-2.90$ & 0.009 & 1.52 & $0.96-2.44$ & 0.077 \\
\hline 2000-2017 & 1.00 & & & & & \\
\hline \multicolumn{7}{|l|}{ Disease-free interval } \\
\hline$<36$ months & 2.09 & $1.34-3.24$ & 0.001 & 2.17 & $1.39-3.37$ & $<0.001$ \\
\hline$\geq 36$ months & 1.00 & & & & & \\
\hline \multicolumn{7}{|l|}{ Surgical procedure } \\
\hline \multicolumn{7}{|l|}{ Number of pulmonary metastases } \\
\hline Multiple & 0.93 & $0.47-1.68$ & 0.821 & & & \\
\hline Solitary & 1.00 & & & & & \\
\hline Tumor diameter & 1.22 & $1.06-1.37$ & 0.006 & 1.21 & $1.02-1.41$ & 0.031 \\
\hline \multicolumn{7}{|l|}{ Lymph node metastasis } \\
\hline Positive & 2.01 & $1.27-3.12$ & 0.003 & 1.75 & $1.06-2.86$ & 0.028 \\
\hline Negative & 1.00 & & & & & \\
\hline \multicolumn{7}{|c|}{ Resection status of pulmonary metastasectomy } \\
\hline \multicolumn{7}{|c|}{ Postoperative therapy after pulmonary metastasectomy } \\
\hline+ & 1.09 & $0.70-1.75$ & 0.705 & & & \\
\hline- & 1.00 & & & & & \\
\hline
\end{tabular}

a, Cox proportional-hazards model. Cl, confidence interval; HR, hazard ratio.

which contain selection bias, high rate of incomplete data, and a long registry period. First, selection bias during data collection by the source registry weakens the significance of the information derived when such data is used to evaluate PM. Second, although 352 patients were eligible for analysis, $99(28.1 \%)$ had no available survival data. Since our database was established by thoracic surgeons, it lacked sufficient information on breast cancer. We recognize this as the greatest limitation of our study. Third, our multiinstitutional database covers a period of 36 years, during which chemotherapy, hormone therapy, and supportive care had improved rapidly. Thus, the results of this study might not reflect real-world metastatic breast cancer patients. Nevertheless, our cohort included 89 patients 
Table 4 Prognostic factors for cancer-specific survival after pulmonary metastasectomy ${ }^{a}$

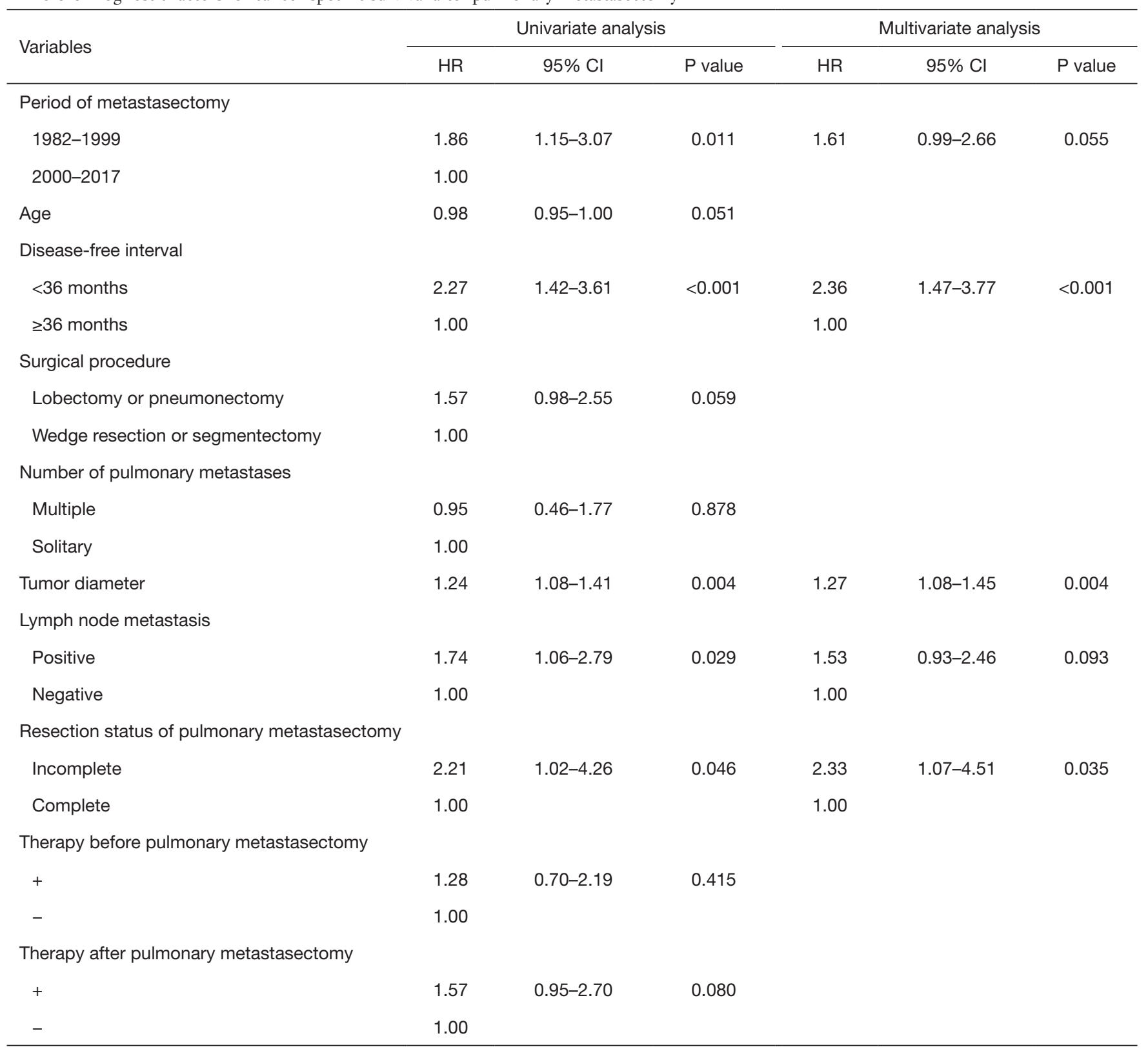

${ }^{\text {a }}$, Cox proportional-hazards model. Cl, confidence interval; HR, hazard ratio.

who underwent surgery relatively recently (2010-2017). Although a meta-analysis of 16 studies demonstrated a 5 -year survival rate of $46 \%$ after PM for pulmonary metastasis of breast cancer (14), those study periods ranged from 1972 to 2007. Thus, despite the limitation involved in covering a large period, we believe that the current study provides relatively recent outcomes of PM for pulmonary metastasis of breast cancer.

\section{Conclusions}

There was no significant difference in overall survival between complete and incomplete resection cases of pulmonary metastasis derived from breast cancer. Therefore, PM for pulmonary metastasis of breast cancer is considered an optional treatment, and it can provide useful information for definitive diagnosis and guiding future treatments. As recommended by a recent guideline (23), a 
Table 5 Patient characteristics according to the extent of resection ${ }^{\mathrm{a}}$

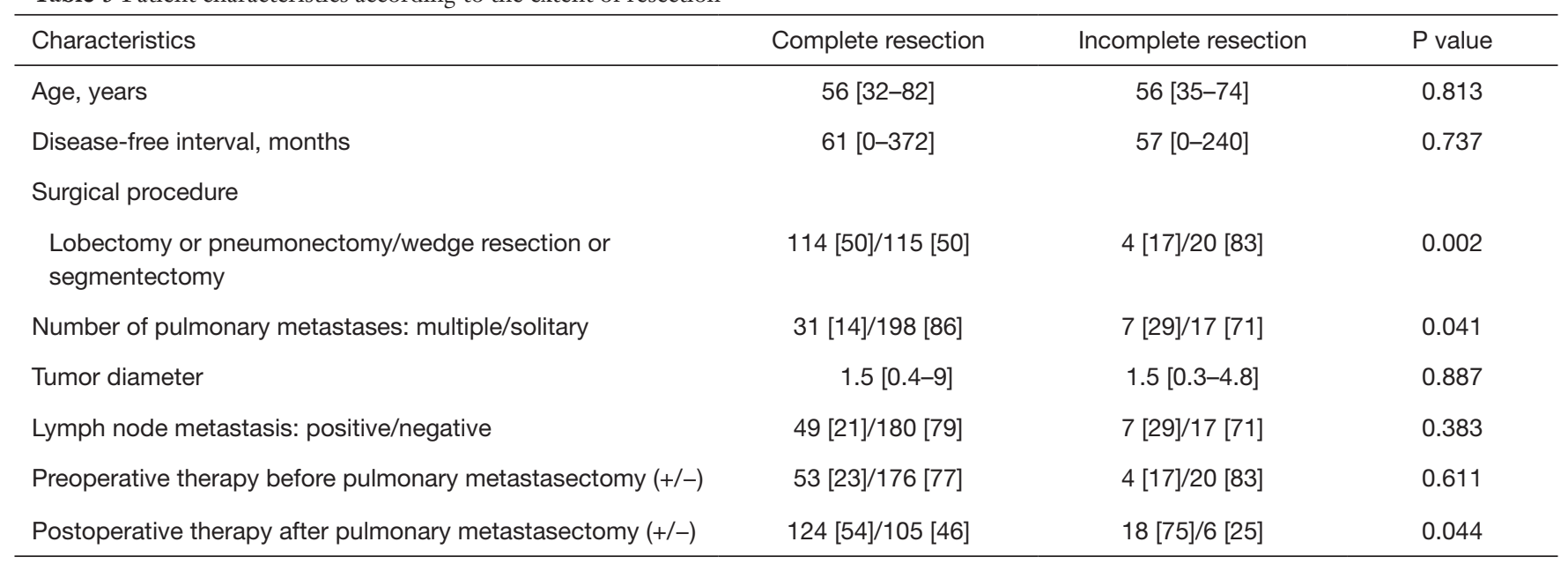

a , categorical variables are shown as numbers (\%) and continuous variables as medians (range). The Chi-square test was used to compare categorical variables. Student's t test or the Wilcoxon rank-sum test was used to compare continuous variables.

Table 6 Studies of pulmonary metastasectomy for pulmonary metastasis of breast cancer published since 2000

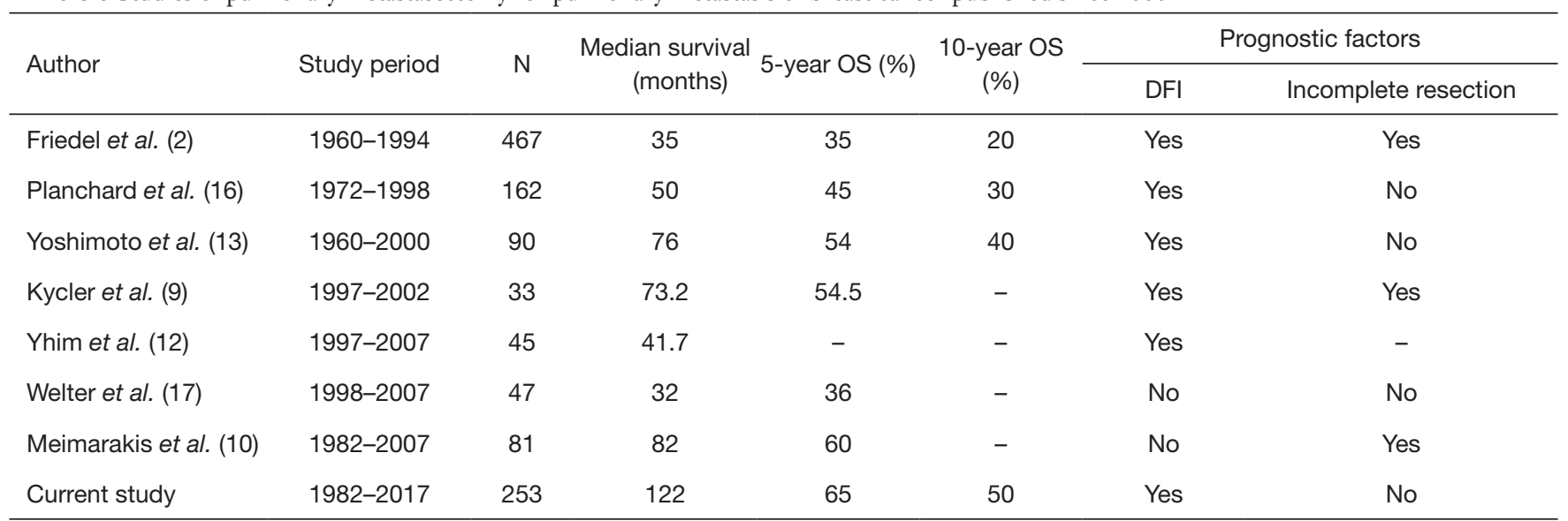

OS; overall survival, DFI, disease-free interval.

multidisciplinary approach is needed.

\section{Acknowledgments}

We are grateful to Ai Yamakawa for management of the database and the secretarial work, and to all members of the Metastatic Lung Tumor Study Group of Japan for data registration. These data were presented at the 19th World Conference on Lung Cancer, Toronto, Canada, September 23-26, 2018.

Funding: None.

\section{Footnote}

Reporting Checklist: The authors have completed the STROBE reporting checklist. Available at http://dx.doi. org/10.21037/jtd-20-1788

Data Sharing Statement: Available at http://dx.doi. org/10.21037/jtd-20-1788

Peer Review File: Available at http://dx.doi.org/10.21037/jtd20-1788 
Conflicts of Interest: All authors have completed the ICMJE uniform disclosure form (available at http://dx.doi. org/10.21037/jtd-20-1788). The authors have no conflicts of interest to declare.

Etbical Statement: The authors are accountable for all aspects of the work in ensuring that questions related to the accuracy or integrity of any part of the work are appropriately investigated and resolved. The study was conducted in accordance with the Declaration of Helsinki (as revised in 2013). The study was approved by the ethics committees of the affiliated institutions (No. 2018-94; 7 March 2018) and the need for individual consent for this retrospective analysis was waived as long as the patient data remain anonymous.

Open Access Statement: This is an Open Access article distributed in accordance with the Creative Commons Attribution-NonCommercial-NoDerivs 4.0 International License (CC BY-NC-ND 4.0), which permits the noncommercial replication and distribution of the article with the strict proviso that no changes or edits are made and the original work is properly cited (including links to both the formal publication through the relevant DOI and the license). See: https://creativecommons.org/licenses/by-nc-nd/4.0/.

\section{References}

1. Bray F, Ferlay J, Soerjomataram I, et al. Global cancer statistics 2018: GLOBOCAN estimates of incidence and mortality worldwide for 36 cancers in 185 countries. CA Cancer J Clin. 2018;68:394-424.

2. Friedel G, Pastorino U, Ginsberg RJ, et al. International Registry of Lung Metastases, London, England. Results of lung metastasectomy from breast cancer: prognostic criteria on the basis of 467 cases of the International Registry of Lung Metastases. Eur J Cardiothorac Surg 2002;22:335-44.

3. Hellman S, Weichselbaum RR. Oligometastases. J Clin Oncol 1995;13:8-10.

4. Pastorino U, Buyse M, Friedel G, et al. Long-term results of lung metastasectomy: prognostic analyses based on 5206 cases. The International Registry of Lung Metastases. J Thorac Cardiovasc Surg 1997;113:37-49.

5. Rena O, Papalia E, Oliaro A, et al. Pulmonary metastases from epithelial tumors: late results of surgical treatment. Eur J Cardiothorac Surg 2006;30:217-22.

6. Treasure T, Milosevic M, Fiorentino F, et al. Pulmonary metastasectomy: what is the practice and where is the evidence for effectiveness? Thorax 2014;69:946-9.

7. Åberg T, Treasure T. Analysis of pulmonary metastasis as an indication for operation: an evidence-based approach. Eur J Cardiothorac Surg 2016;50:792-8.

8. National Comprehensive Cancer Network. NCCN clinical practice guidelines in oncology. Breast Cancer. Ver 3.2019. Available online: www.nccn.com

9. Kycler W, Laski P. Surgical approach to pulmonary metastases from breast cancer. Breast J 2012;18:52-7.

10. Meimarakis G, Rüttinger D, Stemmler J, et al. Prolonged overall survival after pulmonary metastasectomy in patients with breast cancer. Ann Thorac Surg 2013;95:1170-80.

11. Staren ED, Salerno C, Rongione A, et al. Pulmonary resection for metastatic breast cancer. Arch Surg 1992;127:1282-4.

12. Yhim HY, Han SW, Oh DY, et al. Prognostic factors for recurrent breast cancer patients with an isolated limited number of lung metastases and implication for pulmonary metastasectomy. Cancer 2010;116:2890-901.

13. Yoshimoto M, Tada K, Nishimura S, et al. Favourable longterm results after surgical removal of lung metastases of breast cancer. Breast Cancer Res Treat 2008;110:485-91.

14. Fan J, Chen D, Du H, et al. Prognostic factors for resection of isolated pulmonary metastases in breast cancer patients: a systematic review and meta-analysis. J Thorac Dis 2015;7:1441-51.

15. McDonald ML, Deschamps C, Ilstrup DM, et al. Pulmonary resection for metastatic breast cancer. Ann Thorac Surg 1994;58:1599-602.

16. Planchard D, Soria JC, Michiels S, et al. Uncertain benefit from surgery in patients with lung metastases from breast carcinoma. Cancer 2004;100:28-35.

17. Welter S, Jacobs J, Krbek T, et al. Pulmonary metastases of breast cancer. When is resection indicated? Eur $\mathrm{J}$ Cardiothorac Surg 2008;34:1228-34.

18. von Elm E, Altman DG, Egger M, et al.; STROBE Initiative. The Strengthening the Reporting of Observational Studies in Epidemiology (STROBE) statement: guidelines for reporting observational studies. PLoS Med 2007;4:e296.

19. Kawamura M, Nakajima J, Matsuguma H, et al. Surgical outcomes for pulmonary metastases from hepatocellular carcinoma. Eur J Cardiothorac Surg 2008;34:196-9.

20. Thomford NR, Woolner LB, Clagett OT. The surgical treatment of metastatic tumors in the lungs. J Thorac Cardiovasc Surg 1965;49:357-63.

21. Rena O, Papalia E, Ruffini E, et al. The role of surgery in 
the management of solitary pulmonary nodule in breast cancer patients. Eur J Surg Oncol 2007;33:546-50.

22. Tanaka F, Li M, Hanaoka N, et al. Surgery for pulmonary nodules in breast cancer patients. Ann Thorac Surg
2005;79:1711-4.

23. Handy JR, Bremner RM, Crocenzi TS, et al. Expert consensus document on pulmonary metastasectomy. Ann Thorac Surg 2019;107:631-49.
Cite this article as: Endoh M, Shiono S, Yamauchi Y, Mun M, Ikeda N, Hashimoto H, Horio H, Asamura H, Yoshino I, Matsuguma H, Nakajima J, Oyama T, Shintani Y, Nakayama M, Matsutani N, Kawamura M; on behalf of the Metastatic Lung Tumor Study Group of Japan. Pulmonary metastasectomy for pulmonary metastasis of breast cancer has a limited prognostic impact: a multi-institutional retrospective analysis. J Thorac Dis 2020;12(11):6552-6562. doi: 10.21037/jtd-20-1788 